\title{
Nicotinamide Restores Cognition in Alzheimer's Disease Transgenic Mice via a Mechanism Involving Sirtuin Inhibition and Selective Reduction of Thr231-Phosphotau
}

\author{
Kim N. Green, ${ }^{1}$ Joan S. Steffan, ${ }^{2}$ Hilda Martinez-Coria, ${ }^{1}$ Xuemin Sun, ${ }^{3}$ Steven S. Schreiber, ${ }^{3,5}$ \\ Leslie Michels Thompson, ${ }^{1,2,4}$ and Frank M. LaFerla ${ }^{1}$ \\ Departments of ${ }^{1}$ Neurobiology and Behavior, ${ }^{2}$ Psychiatry and Human Behavior, ${ }^{3}$ Neurology, ${ }^{4}$ Biological Chemistry, and ${ }^{5}$ Anatomy and Neurobiology, \\ University of California, Irvine, Irvine, California 92697-4545
}

\begin{abstract}
Memory loss is the signature feature of Alzheimer's disease, and therapies that prevent or delay its onset are urgently needed. Effective preventive strategies likely offer the greatest and most widespread benefits. Histone deacetylase (HDAC) inhibitors increase histone acetylation and enhance memory and synaptic plasticity. We evaluated the efficacy of nicotinamide, a competitive inhibitor of the sirtuins or class III NAD ${ }^{+}$-dependent HDACs in 3xTg-AD mice, and found that it restored cognitive deficits associated with pathology. Nicotinamide selectively reduces a specific phospho-species of tau (Thr231) that is associated with microtubule depolymerization, in a manner similar to inhibition of SirT1. Nicotinamide also dramatically increased acetylated $\alpha$-tubulin, a primary substrate of SirT2, and MAP2c, both of which are linked to increased microtubule stability. Reduced phosphoThr231-tau was related to a reduction of monoubiquitinconjugated tau, suggesting that this posttranslationally modified form of tau may be rapidly degraded. Overexpression of a Thr231phospho-mimic tau in vitro increased clearance and decreased accumulation of tau compared with wild-type tau. These preclinical findings suggest that oral nicotinamide may represent a safe treatment for $\mathrm{AD}$ and other tauopathies, and that phosphorylation of tau at Thr231 may regulate tau stability.
\end{abstract}

Key words: amyloid; transgenic; Alzheimer's disease; vitamin; memory; cognition

\section{Introduction}

Acetylation of histones and nonhistone transcription factors plays an important role in regulating chromatin condensation and gene transcription (Roth et al., 2001). The key enzymes responsible for regulating protein acetylation include the histone acetyltransferases (HATs) and histone deacetylases (HDACs) (Roth et al., 2001). Altered HAT and HDAC activities profoundly affect many critical cellular processes and are linked to several human diseases including cancer, fragile $\mathrm{X}$ syndrome, Rubinstein-Taybi syndrome, and neurodegenerative disorders (Timmermann et al., 2001). HDACs can be divided into four classes based on their homology to yeast proteins and cofactor requirements (McLaughlin and La Thangue, 2004). To date, 11 mammalian HDAC Class I, II, and IV family members have been identified. More recently, homologues of the yeast silent information regulator 2 (Sir2), which are nicotinamide adenine dinucleotide $\left(\mathrm{NAD}^{+}\right)$dependent and comprise the Class III HDACs

\footnotetext{
Received July 9, 2008; revised Aug. 27, 2008; accepted Sept. 7, 2008.

This work was supported in part by a grant from the Alzheimer's Drug Discovery Foundation to S.S.S. and National Institutes of Health Grants AG0212982 to F.M.L. and NS-52789 to L.M.T. We thank Drs. Masashi Kitazawa, Salvatore Oddo, and Mathew Blurton-Jones for helpful discussion and Hasan Khashwji for technical assistance. We also thank Dr. Heidi Rommelaere for the myc-actin plasmid, Dr. Ana Maria Cuervo for the filter retardation assay protocol, and Dr. Frederick Alt for the Sirt1 knock-out mice.

Correspondence should be addressed to Frank M. LaFerla, Department of Neurobiology and Behavior, University

of California, Irvine, 1109 Gillespie Neuroscience Building, Irvine, CA 92697-4545. E-mail: laferla@uci.edu. D0I:10.1523/JNEUROSCI.3203-08.2008

Copyright $\odot 2008$ Society for Neuroscience $\quad 0270-6474 / 08 / 2811500-11 \$ 15.00 / 0$
}

(McLaughlin and La Thangue, 2004), have been identified in mammals. The sirtuin family of deacetylases is implicated in cellular pathways that influence longevity in yeast, C. elegans, Drosophila, and mammals (Tissenbaum and Guarente, 2001; Anderson et al., 2003; Howitz et al., 2003; Wood et al., 2004; Baur et al., 2006).

HDAC inhibitors appear to confer significant neuroprotection in experimental models of neurodegenerative diseases. HDAC inhibitors block polyglutamine-dependent neurodegeneration in transgenic Drosophila and improve motor impairment and neuropathology in transgenic mouse models of both Huntington's disease (HD) and spinal bulbar muscular atrophy (McCampbell et al., 2001; Steffan et al., 2001; Ferrante et al., 2003; Hockly et al., 2003; Minamiyama et al., 2004). In addition to the polyglutamine repeat diseases, beneficial effects of HDAC inhibitors have been reported in animal models of Parkinson's disease (PD), ALS, and experimental autoimmune encephalomyelitis (Gardian et al., 2004; Camelo et al., 2005; Ryu et al., 2005; Fischer et al., 2007). Clinical trials are currently underway to test the efficacy of the Class I/II HDAC inhibitor, sodium phenylbutyrate, in ALS, HD, and PD patients. Notably, there are no published reports testing the efficacy of transcriptional therapy with HDAC inhibitors in experimental models of Alzheimer's disease (AD).

Transcriptional dysfunction has been implicated in the pathophysiology of AD (Robakis, 2003), which is the most common 
neurodegenerative disease of the elderly and characterized by severe memory loss and cognitive decline. The accompanying neuropathology primarily affects the hippocampus, cortex, and amygdala, and includes intraneuronal and extracellular accumulation of the amyloid- $\beta$ ( $\mathrm{A} \beta$ ) peptide, as well as intraneuronal aggregates of the microtubule-associated protein tau into neurofibrillary tangles (NFTs). In view of the clear benefits of HDAC inhibitors in a variety of CNS disorders, we undertook preclinical studies in the $3 \mathrm{xTg}-\mathrm{AD}$ mouse model to determine whether HDAC inhibitors offered any therapeutic benefits (Oddo et al., 2003). The $3 x T g-A D$ mice develop both $A \beta$ and tau pathologies in a spatial and temporal pattern that mimics the human disorder, with coincident cognitive decline. Although HDAC inhibitors such as sodium butyrate increased transgene expression in the $3 x T g-A D$ mice, Class III HDAC inhibitors, such as nicotinamide and sirtinol, did not. When tested for efficacy, our results suggest that nicotinamide is a promising safe and readily available therapeutic for the treatment of $\mathrm{AD}$, as it restores cognitive decline associated with AD pathology. Underlying this, nicotinamide treatment selectively reduces a phosphorylated species of tau associated with microtubule depolymerization and implicated in $\mathrm{AD}$. Treatment also upregulates proteins associated with increased microtubule stabilization and upregulates $\mathrm{p} 25$, which is linked to improved learning and memory.

\section{Materials and Methods}

Cloning. Luciferase cDNA was amplified from construct pGL3 (Promega) using primers Fus-luc-Thy1.2-F GCGTCGACGTGGCTAGCCACCATGGAAGACGCC and Fus-luc-Thy1.2-R CGAGAACCGCGGAATCGATTTACACGGCGATCTTTCC using proofstart PCR (Qiagen). A $100 \mathrm{~nm}$ concentration of this PCR product was fused into pUC18-thy1.2 using In-Fusion Dry-Down PCR Cloning Kit (Clontech) as per manufacturer's instructions. JS5 bacteria were electroporated and colonies grown on agar plates containing $100 \mu \mathrm{g} / \mathrm{ml}$ ampicillin. Colonies were picked and selected for the full Thyl.2 containing the luciferase insert and grown up in LB Broth. Plasmid DNA was extracted using a Maxiprep kit (Qiagen).

The construct encoding T231E Tau mutant in this study was created using the QuikChange Site-Directed Mutagenesis Kit (Stratagene) based on pcDNA-Tau, with a pair of primers GGTGGCAGTGGTCCGTGAGCCACCCAAGTCGCCG and CGGCGACTTGGGTGGCTCACGGACCACTGCCACC. The created mutation was verified by DNA sequencing (Laguna Scientific).

Luciferase assays. HEK293 cells were nucleofected with Thy1.2-luc and dsRed at 1:5 to assess transfection efficiency. Two hundred thousand cells were plated down in each well of a six-well plate and left for $24 \mathrm{~h}$. After this time media was replaced and the cells treated with the various compounds. $24 \mathrm{~h}$ later cells were lysed. For all luciferase assays, lysis buffer and luciferase substrates A and B buffers were used as described by the manufacturer (PharMingen). Luciferase activity was measured for $10 \mathrm{~s}$ with an Analytical Luminescence Laboratory Monolight 2010 Luminometer.

Immunoblotting. Protein extracts were prepared from cells using a break buffer ( $50 \mathrm{~mm} \mathrm{NaH} \mathrm{PO}_{4}, 300 \mathrm{~mm} \mathrm{NaCl}, 10 \mathrm{~mm}$ imidazole, $0.005 \%$ Tween 20 at pH 8.0 with the following inhibitors: $5 \mathrm{~mm}$ butyrate, $5 \mathrm{~mm}$ nicotinamide, phosphatase inhibitor cocktail I and II (Sigma-Aldrich), 1 $\mathrm{mm}$ PMSF, $0.001 \mathrm{mg} / \mathrm{ml}$ aprotinin and leupeptin, $20 \mathrm{~mm}$ $\mathrm{N}$-ethylmaleimide, and Complete Mini Protease Inhibitor Tablets (Roche). Cell lysates were then centrifuged at $16,000 \times g$ for $10 \mathrm{~min}$ and the supernatant taken for soluble protein analysis. Protein extracts were prepared from whole-brain samples by homogenizing in T-per (Pierce Biotechnology) extraction buffer and Complete Mini Protease Inhibitor Tablets (Roche) followed by high speed centrifugation at $100,000 \times g$ for $1 \mathrm{~h}$. The supernatant was taken as the protein extract. Protein concentrations were determined by the Bradford method. Equal amounts of protein $(20-50 \mu \mathrm{g}$ depending on protein of interest) were separated by
SDS/PAGE on a $10 \%$ Bis/Tris gel (Invitrogen), transferred to $0.45 \mu \mathrm{M}$ PVDF membranes, blocked for $1 \mathrm{~h}$ in $5 \%(\mathrm{v} / \mathrm{v})$ nonfat milk in Trisbuffered saline, $\mathrm{pH} 7.5$, supplemented with $0.2 \%$ Tween 20 , and processed as described. Antibodies and dilutions used in this study include 6E10 (1:1000; Signet), CT20 (1:5000; Calbiochem) for C99 and C83, HT7 (1:3000; Innogenetics), AT8 (1:1000; Pierce Biotechnology), AT180 (1: 1000; Pierce Biotechnology), AT270 (1:1000; Pierce Biotechnology), anti-GSK3 $\beta$ (1:3000; BD Transduction) for total GSK3 $\beta$ levels, antiGSK3 $\beta$ ser9 (1:3000; Cell Signaling) for ser9 inactivated GSK3 $\beta$, antiCdk5 (1:3000; Calbiochem), anti-C'-term p35 (1:2000; Santa Cruz Biotechnology) for p25 and p35, anti-ubiquitin (PD41) at 1:1000 (Cell Signaling Technology), anti-acetylated $\alpha$-tubulin (6-11B; 1:2000; Sigma-Aldrich), anti- $\alpha$-tubulin (1:5000; Sigma-Aldrich) antisynaptophysin (1:1000; Sigma-Aldrich) and $\alpha$-actin (1:10,000; SigmaAldrich). Quantitative densitometric analyses were performed on digitized images of immunoblots with Scion Image 4.0 (Scion Corporation).

For filter retardation assay cell debris pellets were taken after centrifugation for $10 \mathrm{~min}$ at $16,000 \times \mathrm{g}$. Pellets were resuspended in $100 \mu \mathrm{l}$ of Tris buffer (20 mM Tris, $15 \mathrm{~mm} \mathrm{MgCl}_{2}$ at $\mathrm{pH} 8.0$ ) and $100 \mu \mathrm{l}$ of $4 \%$ SDS-100 mm DTT in PBS added. These samples were boiled for $5 \mathrm{~min}$ and then filtered through nitrocellulose membrane via a dot blot apparatus. The membranes were then dried at room temperature for $30 \mathrm{~min}$ and then blocked and primary antibodies added. Membranes were then treated at with Western blot for visualization of protein levels.

$A \beta$ ELISA. $\mathrm{A} \beta_{1-40}$ and $\mathrm{A} \beta_{1-42}$ were measured using a sensitive sandwich ELISA system. Soluble and insoluble $A \beta$ was isolated from wholebrain homogenates using T-per extraction buffer (Pierce Biotechnology) and $70 \%$ formic acid (FA) respectively. Soluble fractions were loaded directly onto ELISA plates and FA fractions were diluted 1:20 in neutralization buffer ( $1 \mathrm{M}$ Tris base; $0.5 \mathrm{M} \mathrm{NaH}{ }_{4} \mathrm{PO}_{4}$ ) before loading. Secreted $\mathrm{A} \beta$ was measured from in vitro assays by direct addition of the cell incubated media onto the ELISA plates. MaxiSorp immunoplates (Nunc) were coated with mAB20.1 (William Van Nostrand, Stony Brook University, Stony Brook, NY) antibody at a concentration of $25 \mu \mathrm{g} / \mathrm{ml}$ in coating buffer ( $0.1 \mathrm{M} \mathrm{NaCO}_{3}$ buffer, $\left.\mathrm{pH} 9.6\right)$, and blocked with $3 \%$ BSA. Standards of both $\mathrm{A} \beta_{40}$ and $\mathrm{A} \beta_{42}$ were made in antigen capture buffer (ACB; $20 \mathrm{~mm} \mathrm{NaH} \mathrm{PO}_{4} ; 2$ mm EDTA, $0.4 \mathrm{M} \mathrm{NaCl} ; 0.5 \mathrm{~g}$ of CHAPS; $1 \%$ BSA, pH 7.0), and loaded onto ELISA plates in duplicate. Samples were then loaded in duplicate and incubated overnight at $4^{\circ} \mathrm{C}$. Plates were washed and then probed with either HRP-conjugated anti-A $\beta_{35-40}[\mathrm{C} 49$, for $\mathrm{A} \beta_{1-40}$ (David Cribbs, University of California, Irvine, Irvine, $\mathrm{CA}$ )] or anti-A $\beta_{35-42}\left[\mathrm{D} 32\right.$, for $\mathrm{A} \beta_{1-42}$ (David Cribbs)] overnight at $4^{\circ} \mathrm{C}$. $3,3^{\prime}, 5,5^{\prime}$-Tetramethylbenzidine was used as the chromogen, and the reaction stopped by $30 \% O$-phosphoric acid, and read at $450 \mathrm{~nm}$ on a Molecular Dynamics plate reader. $A \beta$ readings were then normalized to protein concentrations of the samples loaded, or to the protein concentration of the cell layer that the media was incubated with in the case of the in vitro assays. This takes into account any variations of cell numbers or protein concentrations which may otherwise affect $A \beta$ readings.

Immunostaining. Light-level immunohistochemistry was performed using an avidin-biotin immunoperoxidase technique (ABC kit; Vector Laboratories) and was visualized with diaminobenzidine as previously described (Oddo et al., 2003). The following antibodies were used: anti$\mathrm{A} \beta, 6 \mathrm{E} 10$ (Signet Laboratories), anti-Tau HT7 (Innogenetics), AT180 (Innogenetics). Primary antibodies were applied at dilutions of 1:1000 for 6E10; 1:500 for AT180; 1:1000 for HT7.

Immunoprecipitation. One hundred micrograms of whole-brain lysate was incubated with $40 \mu \mathrm{l}$ of Protein A Sepharose beads (Sigma-Aldrich) for $1 \mathrm{~h}$ and centrifuged, and the supernatant was recovered. A further 40 $\mu l$ of beads were added along with HT7 (1:500), and the volume made up to $1 \mathrm{ml}$ with water and incubated overnight at $4^{\circ} \mathrm{C}$ overnight. After pelleting the beads, the supernatant was discarded and the beads washed with STEN buffer $(0.15 \mathrm{M} \mathrm{NaCl}, 0.05 \mathrm{~m}$ Tris $\mathrm{HCl}, 0.002$ м EDTA, $2 \%$ $\mathrm{NP}-40, \mathrm{pH} 7.6$ ), and then STEN containing $0.1 \%$ SDS. The beads were then pelleted and $4 \times$ loading buffer added (Invitrogen), the samples were boiled for $10 \mathrm{~min}$ and spun down again, and the supernatant was run on a $4-12 \%$ Bis-Tris gel (Invitrogen).

Confocal microscopy. Fluorescent immunolabeling followed a standard two-way technique (primary antibody followed by fluorescent secondary 
antibody). Free-floating sections were rinsed in TBS, pH 7.4, and then blocked $(0.25 \%$ Triton X-100, 5\% normal goat serum in TBS) for $1 \mathrm{~h}$. Sections were incubated in primary antibody overnight $\left(4^{\circ} \mathrm{C}\right)$, rinsed in PBS, and incubated $(1 \mathrm{~h})$ in either fluorescently labeled anti-rabbit (Alexa 555, 1:200; Molecular Probes) or anti-mouse secondary antibodies (Alexa 488, 1:200; Molecular Probes). Antibodies were diluted as follows: HT7, 1:1000; AT180, 1:1000; anti-ubiquitin, 1:1000. Omission of primary antibody or use of preimmune IgG eliminated all labeling (data not shown). Confocal images were captured on a Bio-Rad Radiance 2100 confocal system. To prevent signal bleed-through, all fluorophores were excited and scanned separately using lambda strobing.

Animal treatments. All rodent experiments were performed in accordance with animal protocols approved by the Institutional Animal Care and Use Committee at the University of California, Irvine (UCI). The triple-transgenic mice (3xTg-AD) have been described previously (Oddo et al., 2003). Briefly, these mice harbor a knock-in mutation of presenilin $1\left(\mathrm{PS}_{\mathrm{M} 146 \mathrm{~V}}\right)$, the Swedish double mutation of amyloid precursor protein $\left(\mathrm{APP}_{\mathrm{KM} 670 / 671 N \mathrm{NL}}\right)$, and a frontotemporal dementia mutation in tau $\left(\operatorname{tau}_{\mathrm{P} 301 \mathrm{~L}}\right)$ on a $129 / \mathrm{C} 57 \mathrm{BL} / 6$ background. Sirtl knock-out mice were a kind gift from Dr. Frederick Alt (Harvard University, Boston, MA) (Cheng et al., 2003). After treatment, the animals were killed and the brains removed. The brains were immediately dissected in half along the coronal line and one half frozen for biochemical analysis and the other half fixed in $4 \%$ paraformaldehyde. Forty-eight hours later, brains were sliced into $40 \mu \mathrm{m}$ sections using a vibratome.

Statistics. Behavioral scores were analyzed using a multifactor or repeated-measures ANOVA including genotype or treatment as independent variables, and escape latencies during training and probe trial measures as dependent variables. To dissect complex interactions between factors, post hoc Scheffé tests and Bonferroni corrections were used to determine individual differences between groups. Biochemical data were analyzed using planned Student's $t$ tests. For individual planned comparisons, results were reported as significant only when $p<0.05$.

\section{Results \\ Effects of sodium butyrate on $A \beta$ and tau pathology in the 3xTg-AD mice}

We initially set out to explore the effects of sodium butyrate, a non-NAD ${ }^{+}$-dependent Class I/II HDAC inhibitor, on the pathological and cognitive phenotype in aged 3xTg-AD mice. However, sodium butyrate treatment increased APP (which is the holoprotein containing the $\mathrm{A} \beta$ sequence), the $\mathrm{A} \beta$ precursor $\mathrm{C} 99$, the alternative APP cleavage fragment C83, and tau steady-state levels (but not $\mathrm{A} \beta$ ) (supplemental Fig. 1, available at www. jneurosci.org as supplemental material), suggesting that this compound modulates transgene expression, which in the $3 \mathrm{xTg}-\mathrm{AD}$ mice is controlled by the Thy 1.2 promoter. Hence, we developed a novel cell-based promoter assay to specifically test the effects of HDAC inhibitors on transgene expression (Fig. 1). Butyrate increased Thy1.2 promoter activity by $\sim 30$-fold indicating that this HDAC inhibitor treatment affected the transgene promoter directly, precluding investigations into its therapeutic value in this animal model. However, nicotinamide and sirtinol, inhibitors of the $\mathrm{NAD}^{+}$-dependent or Class III HDAC sirtuin family, did not affect Thy1.2 promoter activity. Because of precipitation of sirtinol once injected in vivo, we chose to use nicotinamide, which can be administered orally, to determine its effects on $\mathrm{AD}$ pathology and cognition in the $3 \mathrm{xTg}-\mathrm{AD}$ mice.

Nicotinamide prevents cognitive deficits in AD mouse model Nicotinamide, also known as niacinamide, is a sirtuin inhibitor and the biologically active form of niacin (vitamin B3) which has been widely used clinically for $>40$ years (Knip et al., 2000). Nicotinamide is the precursor for the coenzyme $\beta$-nicotinamide adenine dinucleotide $\left(\mathrm{NAD}^{+}\right)$which is necessary for cellular function and energy metabolism. 3xTg-AD and nontransgenic

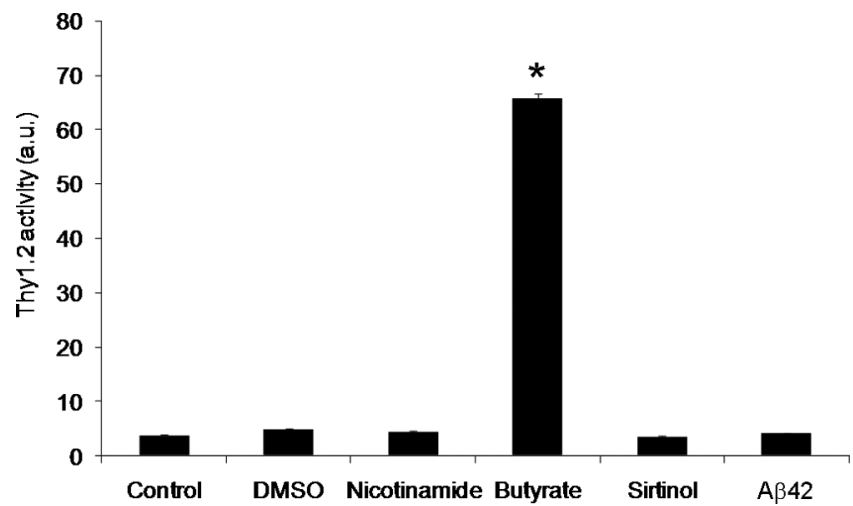

Figure 1. Nicotinamide does not affect thy1.2 promoter. HEK293 cells nucleofected with Thy1.2-luc and then treated with DMSO $(0.1 \%)$, nicotinamide $(5 \mathrm{~mm})$, butyrate $(5 \mathrm{~mm})$, sirtinol $(15 \mu \mathrm{M})$, or $\mathrm{A} \beta_{42}(1 \mu \mathrm{M})$ for $24 \mathrm{~h}$. Luciferase activity was assessed and light output normalized to protein concentration and plotted. Butyrate treatment increased Thy1.2 promoter activity $\sim 30$-fold. Error bars indicate SEM, and * indicates significance versus PBS treatment $(p<$ $0.05)$.

control (NonTg) mice, both 4-months of age at study onset, were given nicotinamide in their drinking water $(200 \mathrm{mg} / \mathrm{kg} / \mathrm{d})$ for 4 months. Cognition was tested on a battery of cognitive tasks to examine hippocampal-, amygdala-, and cortical-dependent learning, which comprise the major brain areas affected by $\mathrm{AD}$ pathology in this mouse model (Oddo et al., 2003). 3xTg-AD mice develop deficits in hippocampal-dependent behavioral tasks in the form of long-term retention deficits by 4 months of age, coinciding with the appearance of intraneuronal $\mathrm{A} \beta$ (Billings et al., 2005). By 8 months, somatodendritic accumulation of phospho- and non-phosphotau also occurs in the hippocampus and amygdala, but not the cortex (Oddo et al., 2003).

3xTg-AD and NonTg mice (which included nicotinamide treated and untreated groups; $n=8$ /group) were tested on the Morris water maze (MWM), a spatial task that is highly dependent on the hippocampus (Sutherland and McDonald, 1990). Treatment of mice with nicotinamide continued throughout the behavioral tasks. Mice were trained to criterion (escape latency $<25$ s) in the spatial reference version of the MWM to find the location of a hidden platform (Billings et al., 2005). Vehicletreated 3xTg-AD mice reached criterion in $6 \mathrm{~d}$, in line with previous findings (Billings et al., 2007), whereas 3xTg-AD mice treated with nicotinamide required only $4 \mathrm{~d}$ (Fig. $2 \mathrm{~A}$ ), suggesting that oral NA treatment improves spatial learning. NonTg mice also reached criterion by the fourth day, and treatment with nicotinamide did not significantly alter acquisition (Fig. $2 A$ ). Spatial reference memory probe trials were conducted at 1.5 and $24 \mathrm{~h}$ after the last training trial to examine short- and long-term memory, respectively. Nicotinamide rescued both short- and longterm memory in the $3 \mathrm{xTg}-\mathrm{AD}$ mice comparable to NonTg mice, as determined by the marked increase in the number of platform crosses and reduced latency to cross the platform (Fig. 2B,C), whereas no change was seen in the time spent in the opposite quadrant (Fig. 2D). Interestingly, nicotinamide treatment in NonTg mice increased the number of platform crosses and decreased the latency to cross the platform only at the $1.5 \mathrm{~h}$ probe trial, suggesting that it may have beneficial effects on short-term memory in nondemented animals (Fig. $2 B, C$ ). However, given that nicotinamide improved $3 \times \mathrm{Tg}-\mathrm{AD}$ acquisition to NonTg levels and also restored long-term retention memory, which is the deficit first apparent in these mice, oral nicotinamide appears to 

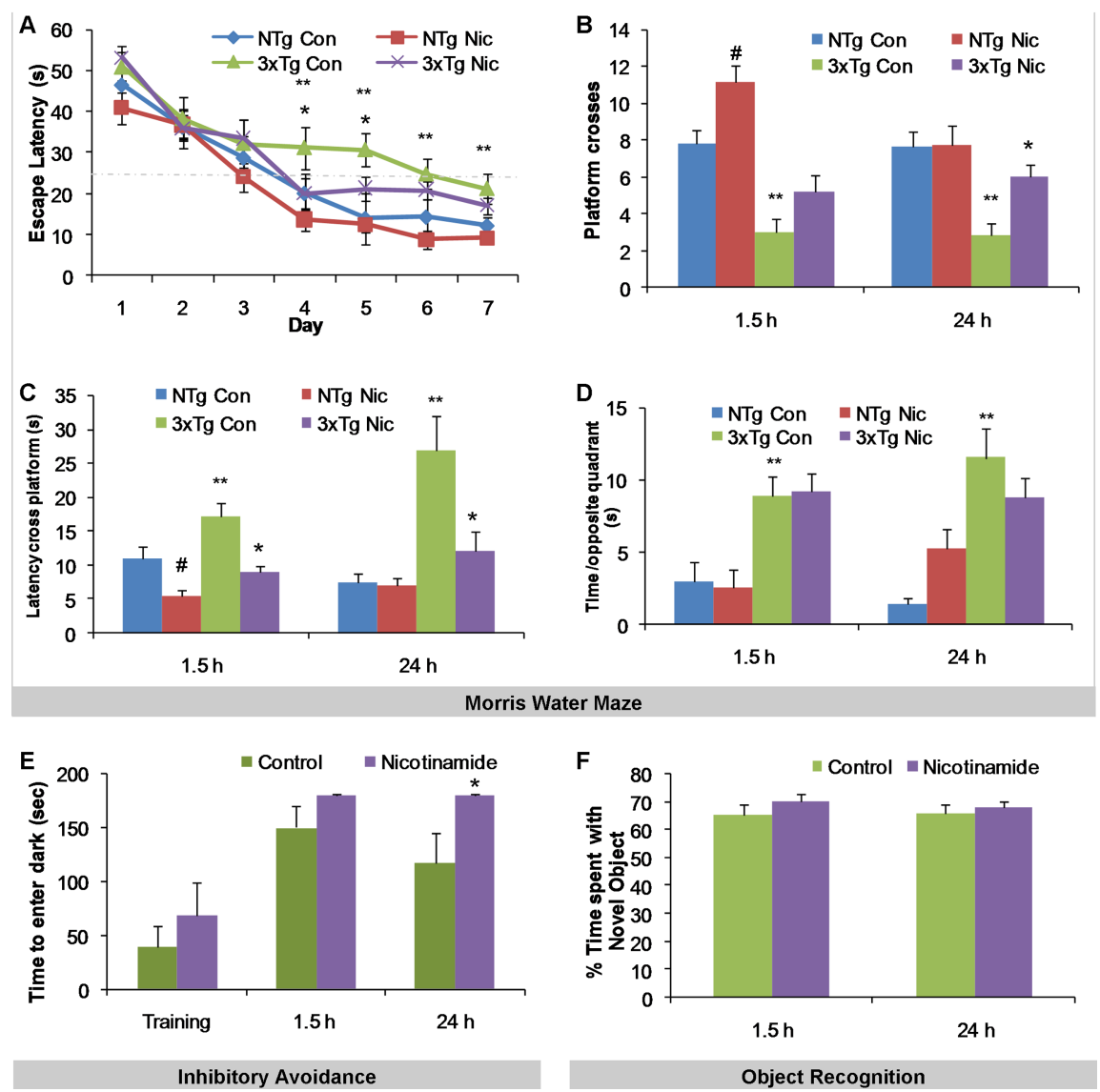

Figure 2. Nicotinamide prevents memory impairments in a hippocampal-dependent task in the 3xTg-AD mice. 3xTg-AD mice were treated with nicotinamide or vehicle for 4 months in their drinking water. Mice were trained and tested on the spatia memory version of the Morris water maze (MWM; $n=8$ per group). $A$, Acquisition curves shown for the $7 \mathrm{~d}$ of training on the MWM. Nicotinamide prevents spatial memory deficits during training in the $3 \times \mathrm{Tg}-\mathrm{AD}$ mice. All mice were trained to criterion in the MWM task (as indicated by dashed line at 25 s escape latency). $\boldsymbol{B}-\boldsymbol{D}$, Mice were given a memory probe with the platform removed at $1.5 \mathrm{~h}$ or $24 \mathrm{~h}$ after the last training trial. $\boldsymbol{B}, 3 \times \mathrm{Tg}-\mathrm{AD}$ mice treated with nicotinamide made significantly more platform crosses at both short- and long-term probes than vehicle-treated 3xTg-AD mice. NonTg mice treated with nicotinamide performed better at the $1.5 \mathrm{~h}$ probe than vehicle treated NonTg mice. C, $3 \times \mathrm{Tg}$-AD mice treated with nicotinamide exhibited significantly decreased latencies to cross the platform location compared with vehicle-treated $3 x \mathrm{Tg}-\mathrm{AD}$ mice, at both the $1.5 \mathrm{and} 24 \mathrm{~h}$ probes. NonTg mice treated with nicotinamide had decreased latencies to cross the platform location compared with vehicle treated nontransgenic mice at only the $1.5 \mathrm{~h}$ probe. $D$, No significant differences in the time spent in the opposite quadrant were seen with nicotinamide treatment compared with vehicle for either $3 \times \mathrm{Tg}-\mathrm{AD}$ or NonTg mice. $\boldsymbol{E}$, Nicotinamide prevents contextual fear memory deficits in a mainly amygdala-dependent task. Mice were tested for retention of memory for fear-associated environments 1.5 and $24 \mathrm{~h}$ after training. Mice were taken out after $180 \mathrm{~s}$ if they did not cross over. $\boldsymbol{F}$, Nicotinamide treatment does not affect cortex-dependent novel object recognition. No significant differences were seen between $3 \mathrm{xTg}-\mathrm{AD}$ mice treated with nicotinamide or vehicle on their ability to remember a prior object, either 1.5 or $24 \mathrm{~h}$ after habituation with the object. Error bars indicate SEM. $\left({ }^{*} p<0.05\right)$ for control 3xTg-AD mice vs nicotinamide treated 3xTg-AD mice, $\left({ }^{* *} p<0.05\right)$ for control nonTg mice vs control 3xTg-AD mice, and $\left({ }^{\#} p<0.05\right)$ for control nonTg mice vs nicotinamide treated nonTg mice.

markedly improve hippocampal-dependent spatial learning in this AD mouse model.

Because 3xTg-AD mice show prominent pathology in the amygdala, we next evaluated the effects of nicotinamide treatment on contextual fear conditioning, an amygdala- and hippocampal-dependent task, using passive inhibitory avoidance. Although 3xTg-AD mice treated with nicotinamide completely avoided the dark, shock-associated compartment at both the $1.5 \mathrm{~h}$ and $24 \mathrm{~h}$ trials after training, vehicle-treated $3 \mathrm{xTg}-\mathrm{AD}$ mice tended to enter this compartment before the $180 \mathrm{~s}$ testing period. This effect was statistically significant after $24 \mathrm{~h}$, and a trend was even evident at $1.5 \mathrm{~h}$ (Fig. $2 \mathrm{E}$ ). These results show that nicotinamide improves contextual learning on an amygdalaand hippocampal-dependent task. Finally, we evaluated nicotinamide-treated and untreated control mice in performance of the cortexdependent contextual task, novel object recognition, which relies on the animals preference to explore a novel object over a familial object (Ennaceur and Delacour, 1988). We found no difference between vehicle- versus nicotinamide-treated 3xTg-AD mice in novel object recognition (Fig. $2 F)$.

These results show that oral nicotinamide treatment prevents the cognitive deficits that manifest in the 3xTg-AD mice, while improving short-term spatial memory in nondemented control animals. After cognitive evaluation, mice were killed and neuropathology assessed to elucidate the underlying mechanism by which nicotinamide improved cognition.

\section{Nicotinamide does not affect A $\boldsymbol{\beta}$ pathology}

We previously showed that soluble $\mathrm{A} \beta$ and soluble tau, which both accumulate within the somatodendritic compartment of neurons, can underlie the cognitive deficits in the 3xTg-AD mice (Oddo et al., 2006). Hence, we sought to determine whether the improved cognitive performance could be attributed to an effect of nicotinamide on $A \beta$ pathology. ELISA analysis of $\mathrm{A} \beta$ levels in both the detergent-soluble and -insoluble fractions from brain homogenates of control and nicotinamidetreated 3xTg-AD mice revealed no statistically significant differences between groups (Fig. $3 A, B$ ). Consistent with the ELISA findings, immunohistochemical staining for $\mathrm{A} \beta$-like immunoreactivity did not reveal any discernable differences in intraneuronal $\mathrm{A} \beta$ accumulation in cell bodies of the hippocampus, amygdala, and cortex between the two groups (Fig. 3A$H)$. Steady-state levels of APP were also unchanged compared with controls, as were levels of $\mathrm{A} \beta^{\star} 56$, an $\mathrm{A} \beta$ oligomer linked to cognitive decline (Lesné et al., 2006), and the C-terminal fragments of APP C83 and C99 (Fig. 3 I, J). These results show that $A \beta$ production is not altered by nicotinamide, and that the beneficial effects of nicotinamide on cognition must occur through another mechanism.

Nicotinamide selectively reduces Thr231 phosphorylated tau Given that nicotinamide improved cognition in both hippocampal- and amygdala-dependent tasks, but had no effect on $\mathrm{A} \beta$ levels, we next investigated its effects on tau pathology. Steady-state levels of human tau (HT7) were significantly reduced by $\sim 20 \%$ in nicotinamide-treated mice compared with controls (Fig. $4 A, B$ ). At 8 months of age, 3xTg-AD mice contain modified tau that is phosphorylated at a number of serine and threonine sites. Steady-state analysis of these phosphotau epitopes revealed no differences in tau phosphorylated at 
A
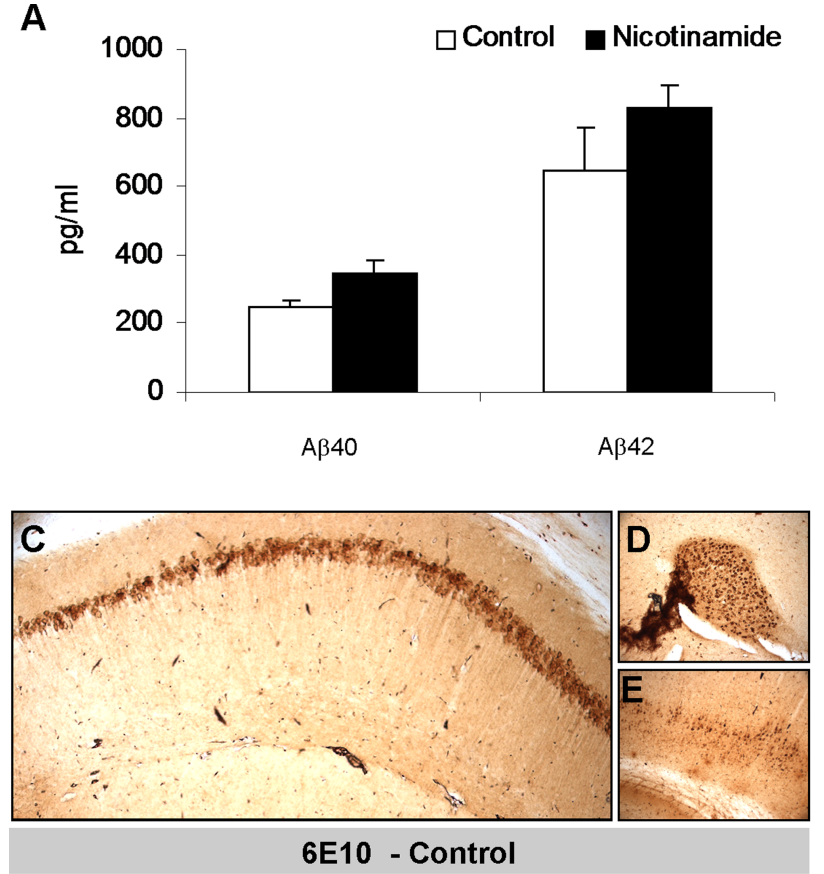

I

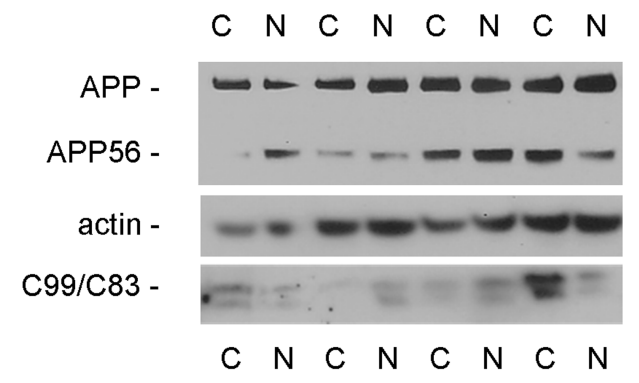

B
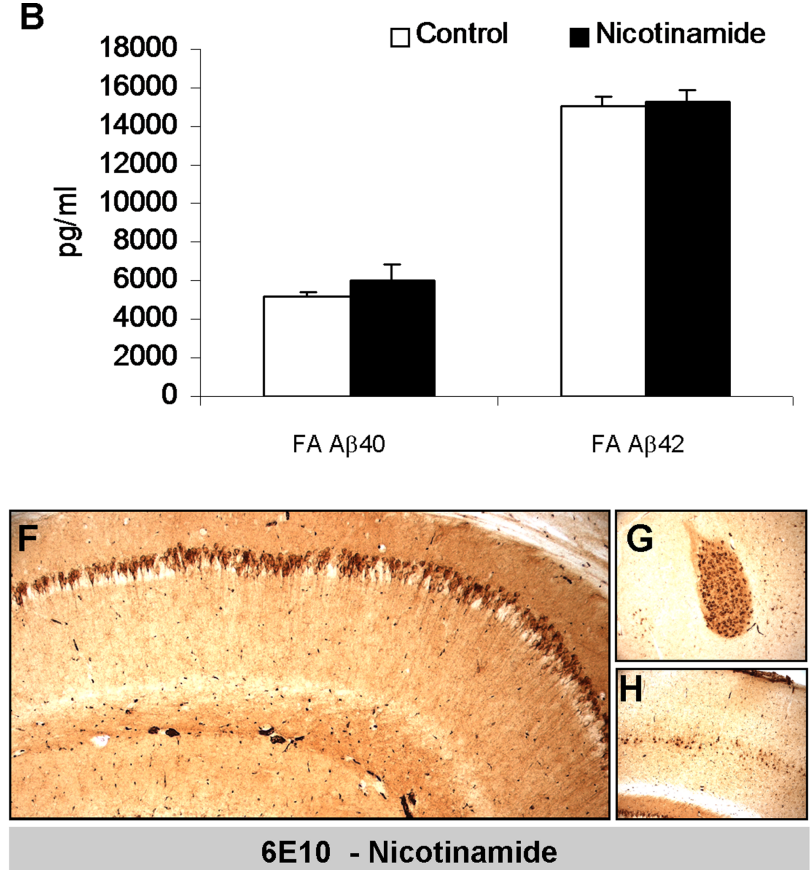

J

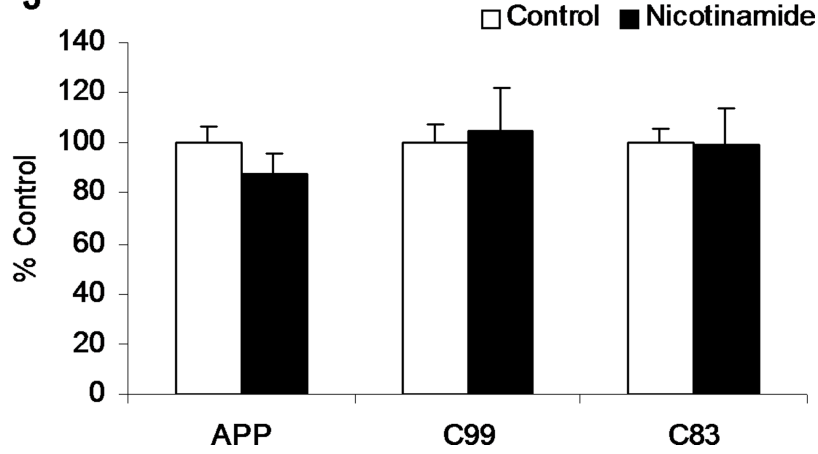

Figure 3. Nicotinamide treatment does not affect $A \beta$ load or production. Soluble $(\boldsymbol{A})$ and insoluble $(\boldsymbol{B}) A \beta_{40}$ and $A \beta_{42}$ levels were measured from $3 x T g-A D$ whole-brain homogenates from animals treated for 4 months with nicotinamide or vehicle. No significant differences were seen between treatments. $\boldsymbol{C}-\boldsymbol{H}$, DAB staining with $6 \mathrm{E} 10$ shows $A \beta$-like immunoreactivity in $40 \mu \mathrm{m}$ sections from nicotinamide- and vehicle-treated mice. Staining was apparent in the hippocampal region $(\boldsymbol{C}, \boldsymbol{F})$, amygdala $(\boldsymbol{D}, \boldsymbol{G})$, and cortex $(\boldsymbol{E}, \boldsymbol{H} ;$ original magnification, $5 \times)$, but no differences were seen with treatment. $I$, Western blot analyses of protein extracts from whole-brain homogenates of $3 \times \mathrm{Tg}$-AD mice treated for 4 months with either nicotinamide (N; $n=8$ ) or vehicle $(C ; n=$ 8) shown as alternating lanes. Steady-state levels of APP and APP CTF's C83 and C 99 were unaffected by nicotinamide treatment. J, Quantification of $I$ normalized to $\beta$-actin levels as a loading control. Error bars indicate SEM.

Thr212/Ser214 (AT100), Ser199/202 (AT8), or Thr181 (AT270) between the nicotinamide- and vehicle-treated mice. Notably, immunoreactivity against Thr231-phosphotau (AT180) was markedly reduced by $>60 \%$ in the nicotinamide group compared with vehicle (Fig. 4A, B). Analysis of insoluble tau levels via filter retardation assay revealed no differences in total human tau, but a trend toward reduction in Thr231-phosphotau that did not reach statistical significance (data not shown).

In vehicle-treated $3 \mathrm{xTg}-\mathrm{AD}$ mice, immunostaining for human tau revealed extensive somatodendritic accumulation in neurons of the hippocampus and amygdala, whereas it was absent in cortex (Fig. $4 \mathrm{C}-\mathrm{H}$ ). Notably, behavior on novel object recognition, a cortex-dependent task, was not improved with nicotinamide treatment (Fig. $2 F$ ), which is consistent with the lack of tau pathology in cortical brain regions at this age.

Using confocal fluorescent microscopy, we assessed ubiquitin and tau localization in hippocampal pyramidal neurons in nicotinamide- and vehicle-treated 3xTg-AD mice. Total human tau staining was apparent throughout the somatodendritic compart- ments and no differences in levels or localization was apparent with treatment (Fig. 4I). Likewise, ubiquitin reactivity (both monoubiquitination and polyubiquitination) and localization were unchanged with nicotinamide treatment, with staining also apparent throughout the somatodendritic compartment. No notable differences in colocalization between ubiquitin and tau were seen. Fluorescent staining for Thr231-phosphotau revealed stark differences: vehicletreated mice displayed abundant staining in the somatodendritic compartment, whereas staining was barely detectable in the nicotinamide-treated mice (Fig. $4 J$ ), illustrating the specific effect on this particular phosphorylated species of tau.

\section{Nicotinamide does not decrease tau kinase activity, but} increases p25

Oral nicotinamide treatment markedly reduced Thr231phosphotau reactivity, but not other phosphotau epitopes examined. Phosphorylation of tau is regulated by various protein kinases and phosphatases. Two major kinases, cyclin-dependent kinase 5 (cdk5) and GSK3 $\beta$, have been shown to participate in the 

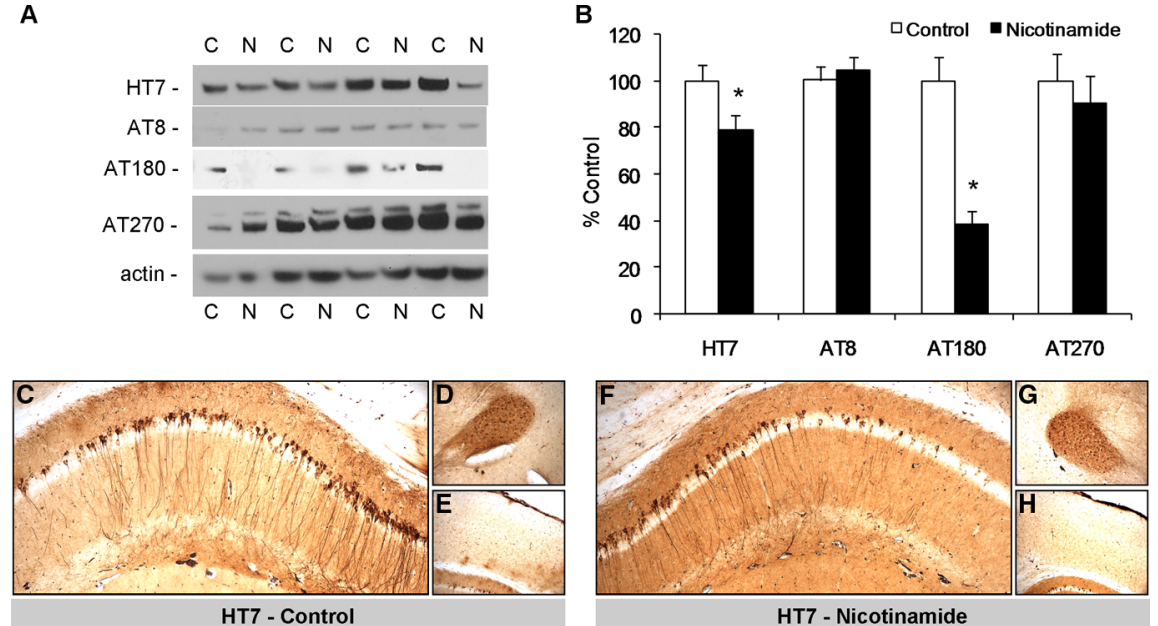

HT7 - Nicotinamide
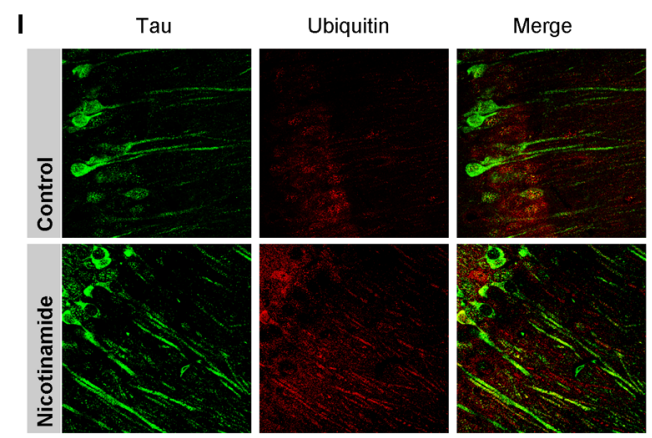

$\mathbf{J}$

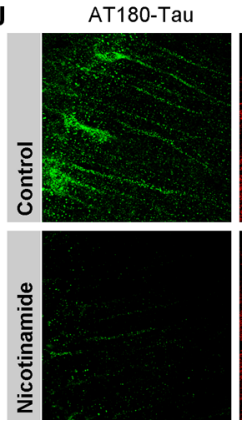

Ubiquitin
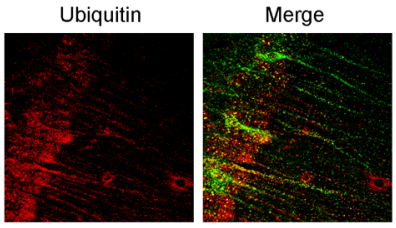

Alt. Merge

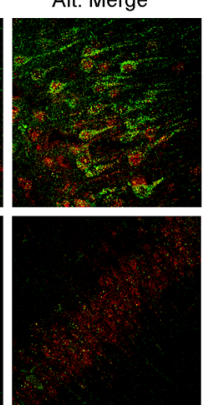

Figure 4. Tau pathology is decreased after nicotinamide treatment. Western blot analyses of protein extracts from wholebrain homogenates of $3 \times \mathrm{Tg}$-AD mice treated for 4 months with either nicotinamide $(\mathrm{N} ; n=8)$ or vehicle $(\mathrm{C} ; n=8)$ shown as alternating lanes. Steady-state levels of total human tau (HT7) and tau phosphorylated at ser199/202 (AT8), thr231 (AT180), and thr181 (AT270) are shown. $\boldsymbol{B}$, Quantification of $\boldsymbol{A}$ normalized to $\beta$-actin levels as a loading control. Error bars indicate SEM, and * indicates significance versus vehicle treatment $(p<0.05$ ). Nicotinamide treatment dramatically reduces Thr213-phosphotau immunoreactivity. $\boldsymbol{C}-\boldsymbol{H}, \mathrm{DAB}$ staining with $\mathrm{HT} 7$ shows human tau immunoreactivity in $40 \mu \mathrm{m}$ sections from nicotinamide- and vehicle-treated mice. Staining was apparent in the hippocampal region $(\boldsymbol{C}, \boldsymbol{F})$, amygdala $(\boldsymbol{D}, \boldsymbol{G})$ but not cortex $(\boldsymbol{E}, \boldsymbol{I}$; original magnification, $5 \times) . \boldsymbol{I}, \boldsymbol{J}$, Confocal microscopy images from $40 \mu \mathrm{m}$ brain sections from nicotinamide- and vehicle-treated $3 \times \mathrm{Tg}-\mathrm{AD}$ mice. (A1 pyramidal neurons shown (magnification $60 \times$ ). Ubiquitin immunoreactivity shown in red for all panels. Total human tau (HT7) reactivity shown in green for I and human tau phosphorylated at thr231 (AT180) reactivity shown in green for J. Merge image shown for both total human tau and ubiquitin and for AT180-tau and ubiquitin.

pathological hyperphosphorylation of tau in both the $3 \mathrm{xTg}-\mathrm{AD}$ mice and in the human brain (Kobayashi et al., 1993; Flaherty et al., 2000). We first examined steady-state levels of GSK3 $\beta$ in $3 x T g-A D$ mice treated with nicotinamide and found no difference compared with untreated animals (Fig. $5 A, B$ ). The activity of GSK $3 \beta$ can be inhibited by phosphorylation of serine 9 (Dajani et al., 2001), such that steady-state levels of this inactive GSK3 $\beta$ can be used to gauge overall activity. We also found no differences in the inactive form of GSK3 $\beta$ (Fig. $6 A, B$ ), suggesting that GSK $3 \beta$ activity is not modulated by nicotinamide treatment. Steady-state levels of cdk5, a second critical tau kinase, were not altered by nicotinamide treatment, but dramatic changes in its coactivator p25 were observed (Fig. 5A,B) (Lew et al., 1994). Increases in p 25 are associated with improved learning and memory and may result as a compensatory mechanism in $\mathrm{AD}$ (Angelo et al., 2003; Fischer et al., 2005).

\section{Nicotinamide reduces \\ monoubiquitinated tau}

Steady-state levels of total tau, as determined by using the antibody HT7, which detects both phospho- and non-phosphotau, were reduced by $\sim 20 \%$ with nicotinamide treatment (Fig. 4A,B). Because we observed a $\sim 60 \%$ reduction in Thr231phosphotau, we considered the possibility that nicotinamide increased degradation of selective phosphotau epitopes. Such an explanation would account for the significantly reduced levels of Thr231phosphotau reactivity and also for the smaller proportion of total tau. In other words, the $\sim 20 \%$ of total tau reduced by this treatment likely represents the tau phosphorylated at the Thr231 site and consequently degraded.

Proteins are tagged for degradation by the addition of ubiquitin and polyubiquitin chains to lysine residues. Total human tau was immunoprecipitated from brain lysates of treated and untreated 3xTg-AD mice and immunoblotted with an anti-ubiquitin antibody. Nicotinamide markedly reduced the presence of monoubiquitinated tau (Fig. 5C); no polyubiquitinated tau was detected perhaps because polyubiquitination is a more transient modification. The relative absence of monoubiquitinated tau in the treatment group means that either monoubiquitinated tau is rapidly degraded, that this compound prevents the ubiquitination in the first place, or that other cellular process involving monoubiquitinated tau are affected. Given that we observed an $\sim 20 \%$ reduction in steadystate levels of total tau, and an $\sim 60 \%$ reduction in Thr231-phosphotau, the most plausible explanation is that nicotinamide increases tau degradation. If this treatment prevented ubiquitination, less degradation might result and hence higher steady-state levels.

\section{Phosphorylation at Thr231 affects the stability and} accumulation of tau

Given our results with nicotinamide in vivo, in which we found a dramatic reduction in Thr231-phosphotau, we sought to determine whether phosphorylation of this residue was important for stability in vitro. Attempts to detect tau Thr231 phosphorylation in cells proved difficult, hence to test the relationship of Thr231 phosphorylation to protein levels, we created a phospho-mimic 
of Thr231 tau by substituting the threonine to a glutamic acid (T231E). Equal amounts of wild-type or the T231Eencoding plasmids were overexpressed in NIH3T3 cells and total levels of tau assessed $24 \mathrm{~h}$ later. To control for transcriptional differences between the two plasmids, we also co-overexpressed myc-actin under the control of the same CMV promoter as the tau constructs (Fig. 5D). Overexpression of the T231E mutant resulted in a significant and highly reproducible reduction in steady-state levels of tau, whereas levels of myc-actin were similar across samples (Fig. 5D,F). These data suggest that phosphorylation at Thr231 likely increases clearance of tau rather than decreasing its production. Furthermore, we examined accumulation of insoluble tau using a filter retardation assay, and show that whereas wild-type tau accumulates, the T231E mutant does not (Fig. $5 E, F)$. These data show that phosphorylation of tau at Thr231 is important for its stability and that phosphorylation at this epitope marks the protein for degradation and thus prevents aggregation and accumulation.

\section{Nicotinamide inhibits brain sirtuin deacetylase function and increases levels of microtubule-stability-associated proteins}

Nicotinamide reverses cognitive deficits associated with $\mathrm{AD}$ pathology in the 3xTg-AD mice, and reduces a specific species of phosphotau (Thr231), while increasing p25 levels. Thr231-phosphotau is one of two species of tau that is known to inhibit microtubule polymerization (Sengupta et al., 1998; Cho and Johnson, 2004), and is a commonly used biomarker for AD in CSF (Ewers et al., 2007). Similarly, p25 expression is associated with improved learning and memory through its role in upregulation of neuronal structural and synaptic proteins (Angelo et al., 2003; Fischer et al., 2005). An impact on microtubule stability would therefore be significant in $\mathrm{AD}$ as tau pathology leads to the breakdown of microtubules leading to impairments in neuronal transport (Alonso et al., 1997; Ebneth et al., 1998; Sengupta et al., 1998; Evans et al., 2000). These impairments may be involved in the synaptic loss and subsequent retrograde degeneration (Terry, 1998; Mandelkow et al., 2003) characteristic of neurodegeneration in AD.

To determine whether nicotinamide treatment affects other structural components of microtubules, we first tested whether $\alpha$-tubulin acetylation is altered in brain. Sirtuins, specifically SirT2, can deacetylate $\alpha$-tubulin (North et al., 2003), the structural component of microtubules. Acetylated- $\alpha$-tubulin is associated with increased microtubule stability (Cambray-Deakin and Burgoyne, 1987) and is decreased in tangle bearing neurons in the AD brain (Hempen and Brion, 1996). Therefore if nicotinamide is delivered to the brain intact and inhibiting sirtuins as predicted, then an increase in acetylated $\alpha$-tubulin should be

A

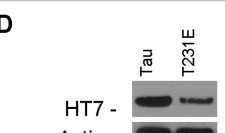

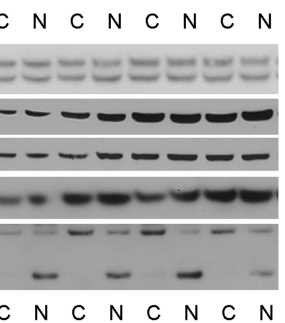

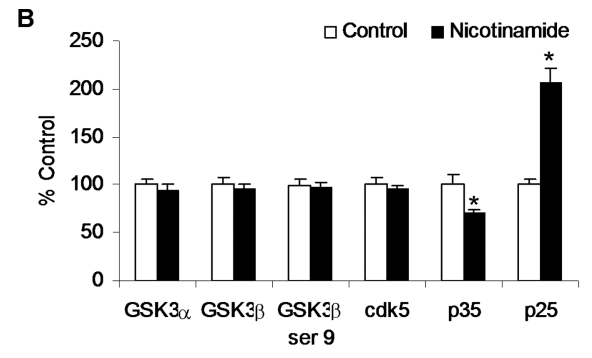

$\mathrm{N} C \mathrm{C} \quad \mathrm{N} \quad \mathrm{N} C \mathrm{C}$

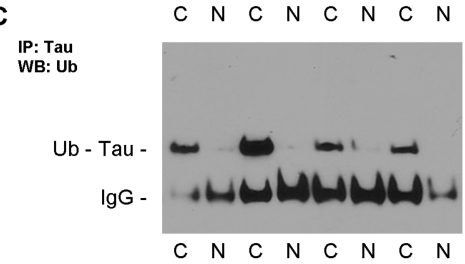

E
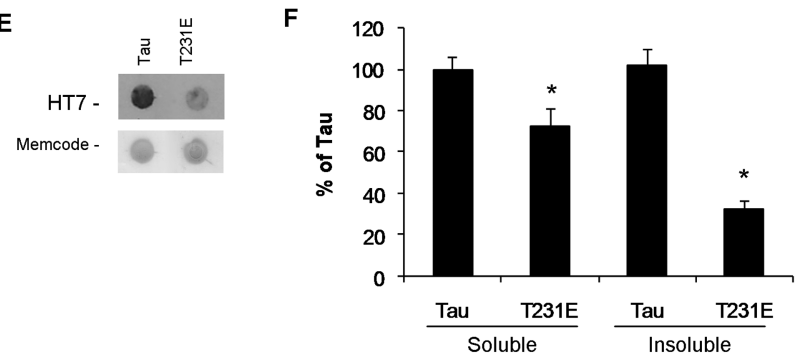

In Vitro overexpression of tau T231 phospho-mimic (T231E)

Figure 5. Nicotinamide treatment increases $p 25$ and reduces monoubiquitinated-tau. Western blot analyses of protein exshown as alternating lanes. Steady-state levels of GSK3 $\alpha / \beta$, inactive GSK3 $\beta$ (phosphorylated at ser9), cdk5 and p35/p25 Q . Memcode protein staining shown as a loading control. $\boldsymbol{F}$, Quantification of $\boldsymbol{D}$ and $\boldsymbol{E}$. Error bars indicate SEM, and ild-type tau $(p<0.05)$

observed. Analysis of brain homogenates from vehicle- and nicotinamide-treated 3xTg-AD mice demonstrated that acetyl$\alpha$-tubulin levels were indeed significantly higher in the animals treated with nicotinamide (Fig. $6 A, B$ ). This effect was even more pronounced for immunoreactive protein corresponding to dimers of acetyl- $\alpha$-tubulin. Notably, steady-state levels of total monomeric or dimeric $\alpha$-tubulin were not altered with nicotinamide treatment (Fig. 6A,B). Hence, increased acetylated $\alpha$-tubulin serves as a useful surrogate marker to monitor nicotinamide-mediated sirtuin inhibition in the brain and suggests a potential impact of nicotinamide on microtubule stability.

Given these robust increases in acetylated $\alpha$-tubulin and p25, we next investigated whether synaptic or other structural proteins associated with the cytoskeleton were altered. No changes in PSD-95, a structural protein that associates with the cytoskeleton and numerous synaptic channels, were detected with nicotinamide treatment (Fig. 6C,D), however a trend toward increased synaptophysin, a synaptic glycoprotein associated with exocytosis, was observed. Microtubule-associated protein 2 (MAP2), an abundant neuronal structural protein that is thought to stabilize 
A
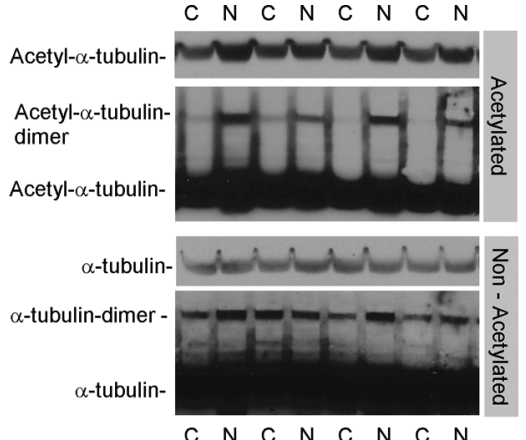

C

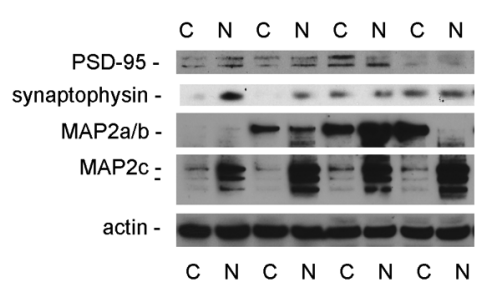

B

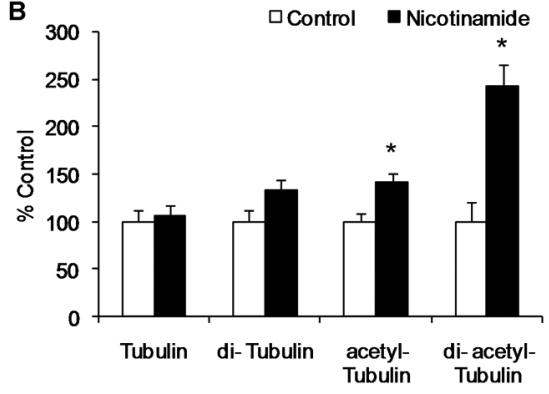

D

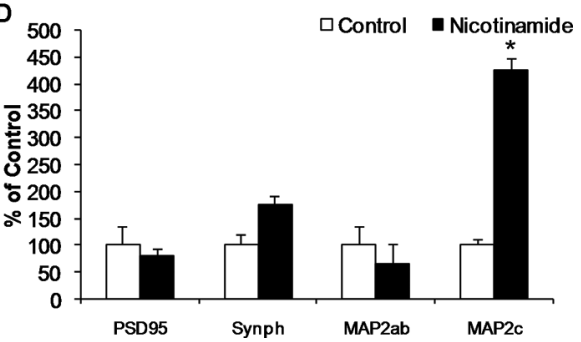

Figure 6. Nicotinamide treatment inhibits brain sirtuins and increase acetylated $\alpha$-tubulin and MAP2c. Western blot analyses of protein extracts from whole-brain homogenates of $3 x \mathrm{Tg}-\mathrm{AD}$ mice treated for 4 months with either nicotinamide $(\mathrm{N} ; n=8)$ or vehicle ( $C ; n=8)$ shown as alternating lanes. $A$, Steady-state levels of acetylated $\alpha$-tubulin showing an increase with nicotinamide treatment, and steady-state levels of a band corresponding to acetyl- $\alpha$-tubulin dimer, which shows a large increase with nicotinamide treatment. Total steady-state levels of monomeric and dimeric $\alpha$-tubulin are also shown, although no differences were evident between nicotinamide and vehicle treatment. B, Quantification of $\boldsymbol{A}$. C, Steady-state levels of PSD-95, synaptophysin, MAP2a, MAP2b, and MAP2c shown. Increases were seen in MAP2c with nicotinamide treatment. $\boldsymbol{D}$, Quantification of $\boldsymbol{C}$ normalized to actin as a loading control. Error bars indicate SEM, and * indicates significance versus vehicle treatment $(p<0.05)$.

A

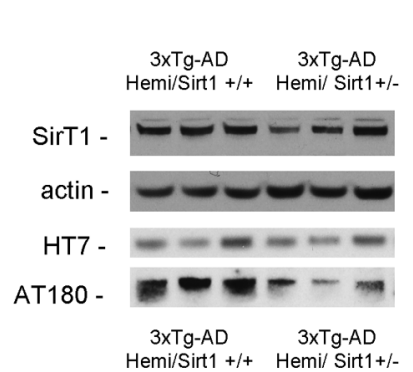

C

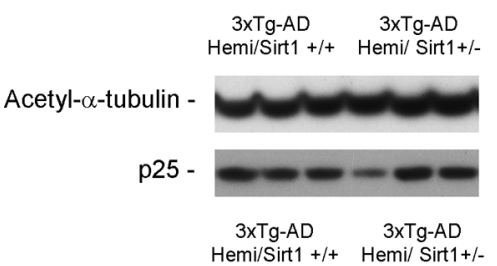

B

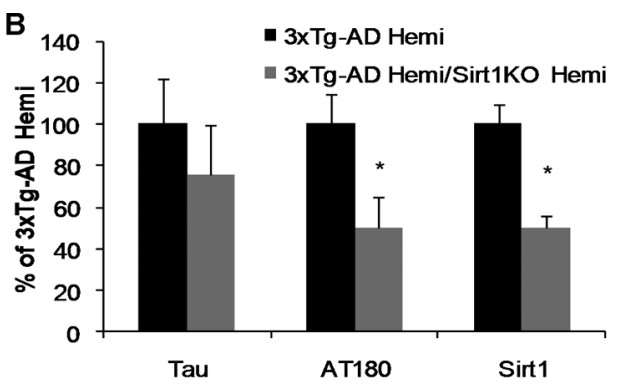

D

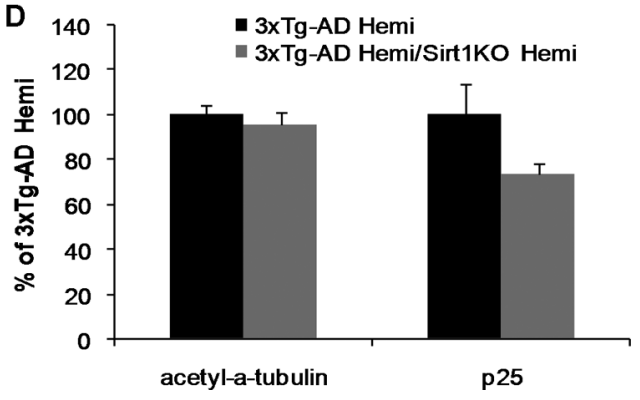

Figure 7. SirT1 knockdown leads to reduced Thr231-phosphotau. Whole-brain homogenates from 12-month-old 3xTg-AD hemizygous mice $(n=6)$ and 12-month-old 3xTg-AD mice with 1 copy of SirT1 knocked out $(n=6)$. $A$, Western blot analyses show a reduction in SirT1 protein levels and Thr231-phosphotau (AT180) in mice lacking a copy of the SirT1 gene. No changes were seen in total human tau (HT7). $\boldsymbol{B}$, Quantification of $\boldsymbol{A}$ normalized to actin as a loading control. $\boldsymbol{C}$, Steady-state levels of acetylated $\alpha$-tubulin and p25 were not altered in mice lacking a copy of SirT1. D, Quantification of $C$ normalized to actin as a loading control. Error bars indicate SEM, and * indicates significance versus vehicle treatment $(p<0.05)$.

microtubule growth, was next investigated. No changes in MAP2a or b were observed, however a robust and dramatic upregulation of MAP2c occurs in nicotinamide treated animals $(>400 \%)$. MAP2c is $80 \%$ homologous to tau within its microtu- bule binding domains (Roger et al., 2004), and the two proteins display similar microtubule binding affinity. These results show that nicotinamide treatment has dramatic effects on proteins associated with the microtubules, from reductions in Thr231-phosphotau, which is known to inhibit microtubule polymerization, to robust increases in acetylated $\alpha$-tubulin and MAP2c.

\section{SirT1 reduction}

\section{reduces Thr231-phosphotau}

Increases in acetylated $\alpha$-tubulin suggests that nicotinamide can enter the brain and inhibit sirtuin function. To assess whether genetic inhibition could evoke a similar molecular signature, we crossed homozygous 3xTg-AD mice with heterozygous SirT1 knock-out mice (Cheng et al., 2003) (homozygous knock-outs are embryonic lethal) because SirT1 is most closely related to yeast sir2. The resultant offspring are strain matched and harbor 1 copy of each of the $\mathrm{AD}$-associated mutant genes (PS1, APP, and tau) and either $2(n=6)$ or $1(n=6)$ copies of SirT1. Mice were aged to 12 months, as pathology develops much slower in hemizygous $3 \times \mathrm{Tg}-\mathrm{AD}$ mice $\left(\mathrm{APP}_{\mathrm{SWE}} / \mathrm{tau}_{\mathrm{P} 301 \mathrm{~L}}+/-, \mathrm{PS}_{\mathrm{M} 146 \mathrm{~V}} / \mathrm{PS} 1\right)$, and then killed and brain tau levels analyzed. Western blot analysis showed no differences in total brain levels of human tau in mice harboring just 1 copy of SirT1 compared with mice with 2 copies (Fig. $7 A, B)$. However, levels of Thr231phosphotau were reduced by $\sim 50 \%$ demonstrating that reductions in SirT1 levels mimic the effects of nicotinamide on tau pathology.

We next examined levels of acetylated $\alpha$-tubulin and p25 in these mice to determine whether SirT1 knockdown could influence their regulation as well, however no significant changes were seen in either, suggesting that SirT1 does not deacetylate $\alpha$-tubulin or lead to increases in p25 (Fig. $7 C, D)$. These data suggest that SirT1 is responsible for regulating levels of Thr231phosphotau, but that increased acetylation of $\alpha$-tubulin and p25 may result from the action of other sirtuins impacted by nicotinamide treatment (e.g., SirT2 for $\alpha$-tubulin) or non-sirtuin-related effects.

\section{Nicotinamide does not reduce Thr231-}

phosphotau in late-stage mice with existing severe pathology

Our original nicotinamide treatment was designed to prevent or delay progression in animals with mild pathology. Treating existing pathologies is far more challenging than preventing the accumulation of pathology in the first place, because of the aggregating nature of tau and $\mathrm{A} \beta$. To determine 
whether nicotinamide could impact severe AD pathology, when tau is highly aggregated into thioflavin-positive tangles (Oddo et al., 2003), we treated 20-month-old 3xTg-AD mice for 4 months with oral nicotinamide as before $(n=5$ untreated vs $n=5$ treated). No behavioral analyses were performed as mice with this severe pathology are unable to learn. In contrast to early treatment, a significant reduction in soluble $A \beta_{42}$ is observed, without changes in the insoluble fraction or soluble $A \beta_{40}$ (supplemental Fig. $2 A, B$, available at www.jneurosci.org as supplemental material). Total human tau (HT7) or Thr231phosphotau (AT180) were unaffected by nicotinamide treatment in these severe pathology mice (supplemental Fig. $2 C, D$, available at www.jneurosci.org as supplemental material). These results show that while nicotinamide is effective in removing Thr231phosphotau in the earlier stages of pathology, it is ineffective at stages when excessive aggregation has occurred. Hence, these results suggest that nicotinamide treatment would be most effective when administered to patients in the early or mild stages of $\mathrm{AD}$, rather than as a treatment for late-stage $\mathrm{AD}$ patients.

\section{Discussion}

Here, we report the novel findings that oral treatment with watersoluble nicotinamide is able to prevent cognitive deficits in a mouse model of AD with mild to moderate pathology in a manner consistent with an inhibition of brain sirtuins and an effect on microtubule stability. Improved memory recollection in nonTg mice treated with nicotinamide was also observed, suggesting that at these doses there are cognition enhancing properties. Nicotinamide was shown to markedly reduce Thr231-phosphotau levels; this particular species of tau has been reported to interfere with microtubule polymerization (Sengupta et al., 1998; Cho and Johnson, 2004), and is a commonly used biomarker for $\mathrm{AD}$ found in CSF (Ewers et al., 2007). Nicotinamide treatment also caused a dramatic upregulation of p25 along with a decrease in p35 (Fig. $5 A, B)$. Such an increase is of relevance to $\mathrm{AD}$ and would normally be associated with increased cdk5 activity and hence increased tau phosphorylation; paradoxically, an increase in phosphotau was not observed with nicotinamide treatment. This observation is in agreement with data showing that moderate overexpression of $\mathrm{p} 25$ does not increase tau phosphorylation, but does lead to improved learning and memory (Angelo et al., 2003). In another $\mathrm{p} 25$ transgenic mouse, transient overexpression of p 25 improved hippocampus-dependent memory and facilitated long-term potentiation (Fischer et al., 2005). Together, these results raise the possibility that chronic but low-level increases in endogenous p25, as seen here after nicotinamide treatment, may improve cognition and behavior and underlie in part the cognitive restoration in the $3 \mathrm{xTg}-\mathrm{AD}$ mice and enhanced cognition in nonTg mice. These previous studies also showed that p25 overexpression caused upregulation of proteins associated with the cytoskeleton and synapses, consistent with the idea that nicotinamide may influence microtubule dynamics, and in agreement we found a trend toward a significant increase in overall steadystate levels of synaptophysin in addition to cytoskeletal associated proteins such as MAP2c. It should be noted that long-term overexpression of p25 leads to substantial neurodegeneration (Fischer et al., 2005), but we saw no evidence of deleterious effects caused by chronic upregulation of endogenous p25. Increased p35 to p25 cleavage is performed by calcium-dependent calpains, and interestingly recent data has shown calpain inhibitors to be protective in AD mouse models (Trinchese et al., 2008). Calpains are thought to have regulatory roles in neurons, but have also been implicated in both apoptosis and necrosis; however we see no evidence for either of these with nicotinamide treatment, either with p53 levels (data not shown), or with other substrates of calpains such as MAP2 (Johnson et al., 1991), which is unchanged or increased with treatment.

Microtubule stability is crucial for elongated cells such as neurons to function. They provide structure and a network for the transport of vital cargo vesicles, and breakdown of this network leads to synaptic loss and neurodegeneration, whereas development of new dendritic structures such as spines, requires a dynamic interaction between microtubules and actin filaments. Tau is a microtubule-associated protein (MAP) that is abundant in neurons and essential for proper stability and functioning of the microtubules that form the cytoskeleton. In contrast, hyperphosphorylation of tau reduces microtubule stabilization leading to reductions in axonal transport (Alonso et al., 1997; Ebneth et al., 1998; Sengupta et al., 1998; Evans et al., 2000). Reductions in transport to the periphery of neurons lead to synaptic starvation, such that synapses are lost in a process known as retrograde degeneration (Terry, 1998; Mandelkow et al., 2003). Hence, Thr231-phosphotau critically influences microtubule dynamics as it promotes microtubule depolymerization (Sengupta et al., 1998; Cho and Johnson, 2004). Although Thr231-phosphotau has been highlighted as crucial for proper tau-microtubule interactions, other phosphotau species have also been identified as impairing microtubule dynamics, such as tau phosphorylated at ser262 (Sengupta et al., 1998) and ser235 (Cho and Johnson, 2004), but it is not clear which ones are most important in vivo, or with regard to cognitive decline. Thus nicotinamide represents an effective treatment which targets this one tau species and leads to cognitive recovery. Phosphorylation of tau at Thr231 can occur via either of the major tau kinases, GSK3 $\beta$ or Cdk5, both of which show increasing activity with increasing age in either $3 \mathrm{xTg}-\mathrm{AD}$ or nonTg mice, but no differences between the two genotypes at 8 months of age (Oddo et al., 2007).

Microtubules are composed of $\alpha$ - and $\beta$-tubulin dimers, and posttranslational modifications such as acetylation and detyrosination increase their stability (Cambray-Deakin and Burgoyne, 1987). SirT2 has been identified to function as an $\alpha$-tubulin deacetylase (North et al., 2003), and treatment by the sirtuin inhibitor nicotinamide dramatically increases both monomeric and dimeric acetylated $\alpha$-tubulin (Fig. $7 A, B$ ), suggesting that nicotinamide treatment may inhibit SirT2 activity in brain. Importantly, in $\mathrm{AD}$ brain acetylated $\alpha$-tubulin is decreased in tangle bearing neurons (Hempen and Brion, 1996), demonstrating the relationship between hyperphosphorylated tau, such as Thr231phosphotau, and breakdown of microtubules. The other predominant MAP in addition to tau is MAP2, which exists as 3 isoforms, MAP2a, MAP2b, and MAP2c, and whose binding to microtubules increases stability in a similar manner to tau. A dramatic upregulation of MAP2c is observed with nicotinamide treatment $(>400 \%)$. Notably, MAP2c is normally more abundant in the neonatal brain than in adult brain, therefore this upregulation may mimic a developmental role for MAP2c. MAP2c shares a up to $80 \%$ identity with tau within the microtubule binding domains (Roger et al., 2004), and has similar microtubule binding kinetics. Unlike tau, MAP2c can also bind F-actin which may be important in neurite initiation and other areas where dynamic cytoskeletal regulation is required (Roger et al., 2004). This profound upregulation of MAP $2 \mathrm{c}$ with nicotinamide treatment likely represents a mechanism to increase microtubule stability. Together these results show that oral nicotinamide treatment mediates pleiotropic effects that appear to converge on the cytoskeleton from the removal of Thr231-phosphotau to po- 
tential increases in microtubule stability via increased acetylated $\alpha$-tubulin and MAP2c.

Nicotinamide affects many cellular pathways in addition to inhibiting sirtuins. It is likely that it mediates its beneficial effects via both sirtuin-dependent and independent pathways. However, nicotinamide may also be targeting multiple sirtuins to exert differential effects. For example, the reduction of Thr231phosphotau is also observed when a single sirtuin, SirT1, is genetically reduced in vivo (Fig. 7C,D). SirT1 knockdown, however, does not affect $\alpha$-tubulin acetylation or p25 levels. These effects may be a consequence of inhibition of other sirtuins, such as SirT2 mediated deacetylation of $\alpha$-tubulin, or other mechanisms may be altered, such as HDAC6 deacetylation of $\alpha$-tubulin. Further experimentation will be required to elucidate the underlying pathways impacted by nicotinamide, such as genetic modulation of other sirtuins or their individual contributions to cognition in 3xTg-AD mice.

Although the most significant finding from this study is that nicotinamide prevents cognitive deficits in an $\mathrm{AD}$ model, it is notable that this beneficial effect coincided with a decrease in Thr231-phosphotau. One possibility is that Thr231-phosphotau degradation is influenced by acetylation and other posttranslational modifications. Recently several proteins have been shown to be degraded through a regulated process involving phosphorylation and monoubiquitination (Wu et al., 2007; Zuccato et al., 2007) consistent with what we observe here in vivo. As this treatment seems to specifically target tau, and, more specifically, Thr231-phosphotau, tau effects may specifically mediate cognitive decline. Recent work suggests that $\mathrm{A} \beta$ causes cognitive decline in $\mathrm{A} \beta$-overproducing $\mathrm{AD}$ mouse models through a mechanism involving tau, as knocking out endogenous murine tau prevents the cognitive decline that normally occurs after $\mathrm{A} \beta$ accumulation (Roberson et al., 2007). Nicotinamide treatment supports this notion that $\mathrm{A} \beta$ modifies tau, which then mediates cognitive decline, and suggests that nicotinamide is promising as a novel therapy. In support of the relationship between Thr231 and degradation, we show that mimicking phosphorylation at the Thr231 site decreases the stability of tau, reducing steady-state levels, aggregation, and accumulation of the protein. As Thr231phosphotau accumulates in $3 \times \mathrm{Tg}-\mathrm{AD}$ mice, but not in nicotinamide-treated animals, it may be that the presence of $\mathrm{A} \beta$ interferes with the normal degradation of tau, as we have previously shown (Tseng et al., 2008), but that the presence of nicotinamide circumvents this outcome.

Previous clinical trials with oral NADH have been performed and showed mixed results (Rainer et al., 2000; Demarin et al., 2004). However, the role of NADH is very different from that of nicotinamide, as the latter compound acts as a more potent inhibitor of the $\mathrm{NAD}^{+}$-dependent sirtuins, as well as serving as a precursor to $\mathrm{NAD}^{+}$, which is converted to NADH through oxidative reduction reactions to produce reducing equivalents for ATP production. Nicotinamide as a beneficial treatment for AD complements a number of emerging studies showing that Sir2 inhibitors improve pathology in other neurodegenerative diseases including Huntington's disease and other models of polyglutamine repeat disorders (Ghosh and Feany, 2004; Pallos et al., 2008) and Parkinson's disease (Outeiro et al., 2007). In the present study, the specific mechanism whereby nicotinamide enhances phosphotau degradation remains to be determined. Furthermore, these results suggest that nicotinamide may also be effective against other tauopathies, which share many common pathological features with the tau pathology seen both in AD and in the $3 \mathrm{xTg}-\mathrm{AD}$ mice. In summary, the results presented here suggest that nicotinamide has potential as a novel, safe, and inexpensive $\mathrm{AD}$ therapy, either alone or in combination with $\mathrm{A} \beta$ lowering therapies.

\section{References}

Alonso AD, Grundke-Iqbal I, Barra HS, Iqbal K (1997) Abnormal phosphorylation of tau and the mechanism of Alzheimer neurofibrillary degeneration: sequestration of microtubule-associated proteins 1 and 2 and the disassembly of microtubules by the abnormal tau. Proc Natl Acad Sci U S A 94:298-303.

Anderson RM, Bitterman KJ, Wood JG, Medvedik O, Sinclair DA (2003) Nicotinamide and PNC1 govern lifespan extension by calorie restriction in Saccharomyces cerevisiae. Nature 423:181-185.

Angelo M, Plattner F, Irvine EE, Giese KP (2003) Improved reversal learning and altered fear conditioning in transgenic mice with regionally restricted p25 expression. Eur J Neurosci 18:423-431.

Baur JA, Pearson KJ, Price NL, Jamieson HA, Lerin C, Kalra A, Prabhu VV, Allard JS, Lopez-Lluch G, Lewis K, Pistell PJ, Poosala S, Becker KG, Boss O, Gwinn D, Wang M, Ramaswamy S, Fishbein KW, Spencer RG, Lakatta EG, et al. (2006) Resveratrol improves health and survival of mice on a high-calorie diet. Nature 444:337-342.

Billings LM, Oddo S, Green KN, McGaugh JL, LaFerla FM (2005) Intraneuronal Abeta causes the onset of early Alzheimer's disease-related cognitive

Billings LM, Green KN, McGaugh JL, LaFerla FM (2007) Learning decreases A beta ${ }^{\star} 6$ and tau pathology and ameliorates behavioral decline in 3xTg-AD mice. J Neurosci 27:751-761. deficits in transgenic mice. Neuron 45:675-688.

Cambray-Deakin MA, Burgoyne RD (1987) Acetylated and detyrosinated alpha-tubulins are co-localized in stable microtubules in rat meningeal fibroblasts. Cell Motil Cytoskeleton 8:284-291.

Camelo S, Iglesias AH, Hwang D, Due B, Ryu H, Smith K, Gray SG, Imitola J, Duran G, Assaf B, Langley B, Khoury SJ, Stephanopoulos G, De Girolami U, Ratan RR, Ferrante RJ, Dangond F (2005) Transcriptional therapy with the histone deacetylase inhibitor trichostatin A ameliorates experimental autoimmune encephalomyelitis. J Neuroimmunol 164:10-21.

Cheng HL, Mostoslavsky R, Saito S, Manis JP, Gu Y, Patel P, Bronson R, Appella E, Alt FW, Chua KF (2003) Developmental defects and p53 hyperacetylation in Sir2 homolog (SIRT1)-deficient mice. Proc Natl Acad Sci U S A 100:10794-10799.

Cho JH, Johnson GV (2004) Primed phosphorylation of tau at Thr231 by glycogen synthase kinase 3 beta (GSK3beta) plays a critical role in regulating tau's ability to bind and stabilize microtubules. J Neurochem 88:349-358.

Dajani R, Fraser E, Roe SM, Young N, Good V, Dale TC, Pearl LH (2001) Crystal structure of glycogen synthase kinase 3 beta: structural basis for phosphate-primed substrate specificity and autoinhibition. Cell 105:721-732.

Demarin V, Podobnik SS, Storga-Tomic D, Kay G (2004) Treatment of Alzheimer's disease with stabilized oral nicotinamide adenine dinucleotide: a randomized, double-blind study. Drugs Exp Clin Res 30:27-33.

Ebneth A, Godemann R, Stamer K, Illenberger S, Trinczek B, Mandelkow E (1998) Overexpression of tau protein inhibits kinesin-dependent trafficking of vesicles, mitochondria, and endoplasmic reticulum: implications for Alzheimer's disease. J Cell Biol 143:777-794.

Ennaceur A, Delacour J (1988) A new one-trial test for neurobiological studies of memory in rats. 1: Behavioral data. Behav Brain Res 31:47-59.

Evans DB, Rank KB, Bhattacharya K, Thomsen DR, Gurney ME, Sharma SK (2000) Tau phosphorylation at serine 396 and serine 404 by human recombinant tau protein kinase II inhibits tau's ability to promote microtubule assembly. J Biol Chem 275:24977-24983.

Ewers M, Buerger K, Teipel SJ, Scheltens P, Schröder J, Zinkowski RP, Bouwman FH, Schönknecht P, Schoonenboom NS, Andreasen N, Wallin A, DeBernardis JF, Kerkman DJ, Heindl B, Blennow K, Hampel H (2007) Multicenter assessment of CSF-phosphorylated tau for the prediction of conversion of MCI. Neurology 69:2205-2212.

Ferrante RJ, Kubilus JK, Lee J, Ryu H, Beesen A, Zucker B, Smith K, Kowall NW, Ratan RR, Luthi-Carter R, Hersch SM (2003) Histone deacetylase inhibition by sodium butyrate chemotherapy ameliorates the neurodegenerative phenotype in Huntington's disease mice. J Neurosci 23:9418-9427.

Fischer A, Sananbenesi F, Pang PT, Lu B, Tsai LH (2005) Opposing roles of 
transient and prolonged expression of p25 in synaptic plasticity and hippocampus-dependent memory. Neuron 48:825-838.

Fischer A, Sananbenesi F, Wang X, Dobbin M, Tsai LH (2007) Recovery of learning and memory is associated with chromatin remodelling. Nature 447:178-182.

Flaherty DB, Soria JP, Tomasiewicz HG, Wood JG (2000) Phosphorylation of human tau protein by microtubule-associated kinases: GSK3beta and cdk5 are key participants. J Neurosci Res 62:463-472.

Gardian G, Yang L, Cleren C, Calingasan NY, Klivenyi P, Beal MF (2004) Neuroprotective effects of phenylbutyrate against MPTP neurotoxicity. Neuromolecular Med 5:235-241.

Ghosh S, Feany MB (2004) Comparison of pathways controlling toxicity in the eye and brain in Drosophila models of human neurodegenerative diseases. Hum Mol Genet 13:2011-2018.

Hempen B, Brion JP (1996) Reduction of acetylated alpha-tubulin immunoreactivity in neurofibrillary tangle-bearing neurons in Alzheimer's disease. J Neuropathol Exp Neurol 55:964-972.

Hockly E, Richon VM, Woodman B, Smith DL, Zhou X, Rosa E, Sathasivam K, Ghazi-Noori S, Mahal A, Lowden PA, Steffan JS, Marsh JL, Thompson LM, Lewis CM, Marks PA, Bates GP (2003) Suberoylanilide hydroxamic acid, a histone deacetylase inhibitor, ameliorates motor deficits in a mouse model of Huntington's disease. Proc Natl Acad Sci U S A 100:2041-2046.

Howitz KT, Bitterman KJ, Cohen HY, Lamming DW, Lavu S, Wood JG, Zipkin RE, Chung P, Kisielewski A, Zhang LL, Scherer B, Sinclair DA (2003) Small molecule activators of sirtuins extend Saccharomyces cerevisiae lifespan. Nature 425:191-196.

Johnson GV, Litersky JM, Jope RS (1991) Degradation of microtubuleassociated protein 2 and brain spectrin by calpain: a comparative study. J Neurochem 56:1630-1638.

Knip M, Douek IF, Moore WP, Gillmor HA, McLean AE, Bingley PJ, Gale EA (2000) Safety of high-dose nicotinamide: a review. Diabetologia 43:1337-1345.

Kobayashi S, Ishiguro K, Omori A, Takamatsu M, Arioka M, Imahori K, Uchida T (1993) A cdc2-related kinase PSSALRE/cdk5 is homologous with the $30 \mathrm{kDa}$ subunit of tau protein kinase II, a proline-directed protein kinase associated with microtubule. FEBS Lett 335:171-175.

Lesné S, Koh MT, Kotilinek L, Kayed R, Glabe CG, Yang A, Gallagher M, Ashe $\mathrm{KH}$ (2006) A specific amyloid-beta protein assembly in the brain impairs memory. Nature 440:352-357.

Lew J, Huang QQ, Qi Z, Winkfein RJ, Aebersold R, Hunt T, Wang JH (1994) A brain-specific activator of cyclin-dependent kinase 5. Nature 371:423-426

Mandelkow EM, Stamer K, Vogel R, Thies E, Mandelkow E (2003) Clogging of axons by tau, inhibition of axonal traffic and starvation of synapses. Neurobiol Aging 24:1079-1085.

McCampbell A, Taye AA, Whitty L, Penney E, Steffan JS, Fischbeck KH (2001) Histone deacetylase inhibitors reduce polyglutamine toxicity. Proc Natl Acad Sci U S A 98:15179-15184.

McLaughlin F, La Thangue NB (2004) Histone deacetylase inhibitors open new doors in cancer therapy. Biochem Pharmacol 68:1139-1144.

Minamiyama M, Katsuno M, Adachi H, Waza M, Sang C, Kobayashi Y, Tanaka F, Doyu M, Inukai A, Sobue G (2004) Sodium butyrate ameliorates phenotypic expression in a transgenic mouse model of spinal and bulbar muscular atrophy. Hum Mol Genet 13:1183-1192.

North BJ, Marshall BL, Borra MT, Denu JM, Verdin E (2003) The human Sir2 ortholog, SIRT2, is an NAD+-dependent tubulin deacetylase. Mol Cell 11:437-444.

Oddo S, Caccamo A, Shepherd JD, Murphy MP, Golde TE, Kayed R, Metherate R, Mattson MP, Akbari Y, LaFerla FM (2003) Triple-transgenic model of Alzheimer's disease with plaques and tangles: intracellular Abeta and synaptic dysfunction. Neuron 39:409-421.

Oddo S, Vasilevko V, Caccamo A, Kitazawa M, Cribbs DH, LaFerla FM (2006) Reduction of soluble Abeta and tau, but not soluble Abeta alone, ameliorates cognitive decline in transgenic mice with plaques and tangles. J Biol Chem 281:39413-39423.
Oddo S, Caccamo A, Cheng D, Jouleh B, Torp R, LaFerla FM (2007) Genetically augmenting tau levels does not modulate the onset or progression of Abeta pathology in transgenic mice. J Neurochem 102:1053-1063.

Outeiro TF, Kontopoulos E, Altmann SM, Kufareva I, Strathearn KE, Amore AM, Volk CB, Maxwell MM, Rochet JC, McLean PJ, Young AB, Abagyan R, Feany MB, Hyman BT, Kazantsev AG (2007) Sirtuin 2 inhibitors rescue alpha-synuclein-mediated toxicity in models of Parkinson's disease. Science 317:516-519.

Pallos J, Bodai L, Lukacsovich T, Purcell JM, Steffan JS, Thompson LM, Marsh JL (2008) Inhibition of specific HDACs and sirtuins suppresses pathogenesis in a Drosophila model of Huntington's disease. Hum Mol Genet. Advance online publication. Retrieved October 8, 2008. doi: $10.1093 / \mathrm{hmg} / \mathrm{ddn} 273$.

Rainer M, Kraxberger E, Haushofer M, Mucke HA, Jellinger KA (2000) No evidence for cognitive improvement from oral nicotinamide adenine dinucleotide (NADH) in dementia. J Neural Transm 107:1475-1481.

Robakis NK (2003) An Alzheimer's disease hypothesis based on transcriptional dysregulation. Amyloid 10:80-85.

Roberson ED, Scearce-Levie K, Palop JJ, Yan F, Cheng IH, Wu T, Gerstein H, Yu GQ, Mucke L (2007) Reducing endogenous tau ameliorates amyloid beta-induced deficits in an Alzheimer's disease mouse model. Science 316:750-754.

Roger B, Al-Bassam J, Dehmelt L, Milligan RA, Halpain S (2004) MAP2c, but not tau, binds and bundles F-actin via its microtubule binding domain. Curr Biol 14:363-371.

Roth SY, Denu JM, Allis CD (2001) Histone acetyltransferases. Annu Rev Biochem 70:81-120.

Ryu H, Smith K, Camelo SI, Carreras I, Lee J, Iglesias AH, Dangond F, Cormier KA, Cudkowicz ME, Brown RH Jr, Ferrante RJ (2005) Sodium phenylbutyrate prolongs survival and regulates expression of antiapoptotic genes in transgenic amyotrophic lateral sclerosis mice. J Neurochem 93:1087-1098.

Sengupta A, Kabat J, Novak M, Wu Q, Grundke-Iqbal I, Iqbal K (1998) Phosphorylation of tau at both Thr 231 and Ser 262 is required for maximal inhibition of its binding to microtubules. Arch Biochem Biophys 357:299-309.

Steffan JS, Bodai L, Pallos J, Poelman M, McCampbell A, Apostol BL, Kazantsev A, Schmidt E, Zhu YZ, Greenwald M, Kurokawa R, Housman DE, Jackson GR, Marsh JL, Thompson LM (2001) Histone deacetylase inhibitors arrest polyglutamine-dependent neurodegeneration in Drosophila. Nature 413:739-743.

Sutherland RJ, McDonald RJ (1990) Hippocampus, amygdala, and memory deficits in rats. Behav Brain Res 37:57-79.

Terry RD (1998) The cytoskeleton in Alzheimer disease. J Neural Transm Suppl 53:141-145.

Timmermann S, Lehrmann H, Polesskaya A, Harel-Bellan A (2001) Histone acetylation and disease. Cell Mol Life Sci 58:728-736.

Tissenbaum HA, Guarente L (2001) Increased dosage of a sir-2 gene extends lifespan in Caenorhabditis elegans. Nature 410:227-230.

Trinchese F, Fa' M, Liu S, Zhang H, Hidalgo A, Schmidt SD, Yamaguchi H, Yoshii N, Mathews PM, Nixon RA, Arancio O (2008) Inhibition of calpains improves memory and synaptic transmission in a mouse model of Alzheimer disease. J Clin Invest 118:2796-2807.

Tseng BP, Green KN, Chan JL, Blurton-Jones M, Laferla FM (2008) Abeta inhibits the proteasome and enhances amyloid and tau accumulation. Neurobiol Aging 29:1607-1618

Wood JG, Rogina B, Lavu S, Howitz K, Helfand SL, Tatar M, Sinclair D (2004) Sirtuin activators mimic caloric restriction and delay ageing in metazoans. Nature 430:686-689.

Wu RC, Feng Q, Lonard DM, O’Malley BW (2007) SRC-3 coactivator functional lifetime is regulated by a phospho-dependent ubiquitin time clock. Cell 129:1125-1140.

Zuccato E, Blott EJ, Holt O, Sigismund S, Shaw M, Bossi G, Griffiths GM (2007) Sorting of Fas ligand to secretory lysosomes is regulated by monoubiquitylation and phosphorylation. J Cell Sci 120:191-199. 